\title{
A Note on the Invention, Invisibility and Dissolution of the Placebo Effect
}

Lars Ole Andersen

Keywords: placebo; placebo effect; imagination; suggestion; mind

In 1945 the American professor of medicine O. H. Perry Pepper wrote under the heading $A$ note on the placebo:

It is interesting that apparently there has never been a paper published discussing the important subject of the placebo. [...] Every one of us has often used the word and often prescribed the placebo, yet how many of us realise how little has been written and how little is known of the history of this word and this type of treatment. ${ }^{1}$

In the 1950s an increasing number of articles about the subject were published ${ }^{2}$. Especially one of these articles became well known and is often mentioned today: it is Henry K. Beecher's article from 1955 entitled The Powerful Placebo ${ }^{3}$. Beecher claimed in this article that in 1,082 patients in 15 studies on 9 different diseases or symptoms $35 \%$ of the patients were satisfactorily relieved by a placebo. He defined the total drug effect as equal to its active effect plus its placebo effect. This was a common understanding of the placebo effect in the 1950s. In 1956 the Danish physician Jacob KjærLarsen wrote that placebo reactions could be caused by spontaneous changes in the disease, accidental coinciding factors, conditioned reflexes or suggestion $^{4}$. These definitions were later criticised, especially in the 1990s, where the total drug effect was not seen as an addition of the active effect of the treatment and the placebo effect. The placebo effect was instead singled out as one out of many effects besides the active effect of the treatment. These

1 Pepper 1945, 409.

2 Shapiro 1960.

3 Beecher 1955.

4 Kjær-Larsen 1956.

Lars Ole Andersen, Medical Museion, University of Copenhagen, Fredericiagade 18, DK-1310 Copenhagen (la@mm.ku.dk) 
effects could, besides the placebo effect, derive from unidentified parallel interventions, bias, confounder, regression to the mean, chance, other unknown factors and the natural development of the disease ${ }^{5}$. In 1997 the Germans Gunver S. Kienle and Helmuth Kiene criticised the use of the word "placebo effect" and argued that the concept of a powerful placebo was fiction ${ }^{6}$. And in 2001 a meta-analysis which analysed the difference between patients in clinical trials who had received placebo and patients who had no treatment, did not find evidence for a substantial placebo effect ${ }^{7}$. The placebo effect seemed to be invisible. Beecher's claim that the placebo effect was powerful was seen as a mistake. In a historical perspective I would rather argue that the definition of the placebo effect has changed. What before was included in the definition is now excluded. But this is not the only change that is connected to the use of the concepts "placebo" and "placebo effect". Other changes have taken place in medicine and the historiography of the placebo effect.

\section{The use of placebos on the ocean of the personal relationship between doctor and patient}

The most comprehensive book on the history of the placebo effect until now is Arthur K. and Elaine Shapiro's book The Powerful Placebo from 1997. It is based on their work on the placebo effect during the last 40 years. It describes how placebo was a part of treatment also in prehistoric time. The description is chronological from prehistory, ancient Greece, China, India, European Galenic medicine to modern medicine in the 20th century. There is a description of the use of the word "placebo", considerations on unconventional methods of treatment, but the greatest part of the book is on trials and their use of blinding, double-blinding and placebos in the 20th century. The description is detailed, based on primary sources, interviews or descriptions of their own research on the placebo effect. The description of the time before the 20th century is, however, mostly based on secondary sources.

Shapiro and Shapiro think that the history of medicine is mainly the history of use of placebo or placebo effect: "The history of medical treatment was essentially the history of the placebo effect [and] the treatments [...] were, as were all remedies of the ancient cultures, placebos." ${ }^{8}$ The point is that

\footnotetext{
5 Resch/Ernst 1996.

6 Kienle/Kiene 1997. See also Kienle 1995 and Kiene 1993.

7 Hróbjartsson/Gøtzsche 2001.

8 Shapiro/Shapiro 1997, 2 f.
} 
nearly nothing of what the physicians, healers, shamans, etc. did, had any effect on the patient's disease. If the patients or the healers thought it worked, it must have been because of the placebo effect or spontaneous improvement. Shapiro and Shapiro define the placebo effect as "primarily the nonspecific psychological or psychophysiological therapeutic effect produced by a placebo, but may be the effect of a spontaneous improvement attributed to the placebo". Placebo is defined as "any treatment (including drugs, surgery, psychotherapy, and quack therapy) that is used for its ameliorative effect on a symptom or disease, but that actually is ineffective or is not specifically effective for the condition being treated"10. From this perspective the placebo effect is a phenomenon thousands of years old and the placebo a treatment which has existed as long as healing itself. This has often been claimed since W. R. Houston in his article "The doctor himself as a therapeutic agent" from 1938 had described the history of medicine as an ocean voyage where the personal relationship between doctor and patient was an unending green waste of water ${ }^{11}$. Treatment which had an effect in itself was like when you sometimes saw a spouting whale, a flying fish or a bit of driftwood.

These statements on the placebo effect are, from the perspective of historiography, not without problems. One of them is that it is the past judged by the concepts from the present, which in the literature is called presentism ${ }^{12}$. In earlier times the effect of treatment was not explained by the placebo effect, but by the influence from God or spirits, excretion of poisonous matter, balancing of the humours or the tranquillising or stimulating effects of the medicine. The idea that something can be a placebo or a placebo effect belongs to a specific historical period which began at the end of the 18th century and lasts until today. Another problem is that when it is not clear in the present how placebo and the placebo effect is best defined it is also difficult to define what the history of the placebo and the placebo effect consists of. Shapiro and Shapiro write: "A placebo therapy may be used with or without knowledge that it is a placebo. Included among placebos are treatments that are given in the belief that they are effective but that actually are placebos by objective evaluation." ${ }^{13}$ This definition could justify the use of the placebo concept back in time, but I think it is problematic to take the placebo concept out of the historical context. The intention with the placebo was that it

9 Shapiro/Shapiro 1997, 1.

10 Shapiro/Shapiro 1997, 1.

11 Houston 1938.

12 Stocking 1965; Kuklich 1999.

13 Shapiro/Shapiro 1997, 1f. 
was a treatment deprived of its usual effect. It is possible that in earlier times some healers would consciously give medicine without any effect only to gain a psychological impact or to "influence the spirits", but this has not been an "ocean" or the great majority of all treatments.

\section{The invention of the placebo}

The first known use of the word placebo ("I will please" in Latin) in its medical meaning stems from 1772 where the professor of medicine William Cullen in a lecture said:

Mr Gilchrist will bear me testimony that at first view I considered him as absolutely incurable, and as hasting very fast to his fate, and I took him in hopes of making some observant upon his case, and even of learning something by his death, I prescribed therefore in pure placebo, but I make it a rule even in employing placebos to give what would have a tendency to be of use to the patient. ${ }^{14}$

Here we get the information that placebo for Cullen was what today would be called impure placebo. It means a treatment, which has an effect, but not on the patient's actual disease. In his book Hospital Life in Enlightenment Scotland Günther Risse writes on therapy in hospitals in Edinburgh at the end of the 18th century, that placebo was often used, when physicians were uncertain what the nature of the disease was, when they wanted to gain time or in hopeless cases where relief was the only thing left ${ }^{15}$.

Cullen mentioned two purposes of the treatment: "in hopes of making some observant upon his case, and even of learning something by his death" and "to give what would have a tendency to be of use to the patient". On the one hand the situation was like a trial, on the other he wanted to benefit the patient. These two purposes have followed the use of noneffective treatments ever since they came into use in the second half of the 18th century. Noneffective treatments were applied in trials on mesmerism in 1784, on "Perkins tractors" in 1799 and on homoeopathy in $1835^{16}$. This function of the placebo was first explicitly connected to definitions of placebo from the 1950 s, probably because trials with the use of noneffective treatment before that time were rare. The other function, to amuse or please the patient, appears from the definitions of placebo throughout the 19th century until today. From the beginning of the 19th century it was also called "pious fraud".

14 Cullen 1772, $218 f$.

15 Risse 1986, 201.

16 Stolberg 1996; Kaptchuk 1998b; Andersen 2004. 
Discussions on this use of placebo became prominent in journals in the last quarter of the century ${ }^{17}$.

The concept must already have been in use before 1772 , since Cullen uses it with no further explanation. In Motherby's New Medical Dictionary from 1785 placebo is defined as "A common place method or medicine". The life of the placebo before that time, probably communicated from physician to physician and given from physician to patient, is yet unknown and is another part of the many silent, invisible lives of the placebo.

\section{The placebo effect}

The word "placebo effect" arose in the 1950s. Before that time the eventual effect of noneffective treatment was mainly explained by "the mind's influence upon the body", "the power of imagination" or "suggestion". In the 18th and 19th centuries imagination, impression, fancy, medical faith and hope constituted a semantic field. Especially the concept of imagination was important ${ }^{18}$. The concepts could in specific contexts be used interchangeable but they were all used to explain how the mind could influence the body. During the 19th century imagination lost its explanatory power and was associated with treatments which were supposed to be dangerous and weakening for the patient (mesmerism) or not effective (Perkins tractors, homoeopathy). Physicians like John Haygarth and Daniel Hack Tuke tried to revitalise the term but they were not successful ${ }^{19}$. Instead Hippolyte Bernheim was more successful with the term "suggestion" which also became successful in sociology ${ }^{20}$.

Then in the 1950s the term "placebo effect" emerged and the articles mentioned in the beginning about how little was written on this interesting and underreported subject. In the last 20 years the subject in a second wave of interest has heavily been debated but as Asbjørn Hróbjartsson has pointed out there have been quite different understandings of the placebo effect in the literature ${ }^{21}$. The three main types are:placebo effect meaning change after placebo medication, placebo effect meaning effect of placebo intervention or placebo effect meaning effect of patient-provider interaction. And there is still no consensus on the best definition of placebo or placebo effect.

17 Brody 1980, 96ff.

18 Andersen 2004.

19 Haygarth 1801; Tuke 1872 and 1884.

20 Faber 1996.

21 Hróbjartsson 2002. 
The message in many of the books on the subject from the last 20 years is that this is a complicated area that needs a multi- or interdisciplinary exploration and much further research ${ }^{22}$. Different theories on the role of expectation, motivation, conditioned reflexes or culture are presented. Some of the books focus on the patient/health provider relationship and the psychological aspects ${ }^{23}$. An interesting aspect in some of the latest publications is that they argue for a replacement of the concept of a placebo effect with concepts like confidence, meaning response or belief effect ${ }^{24}$. There have also been attempts to, instead of placebo effect, use less-loaded or troublesome words like caring effects, health resources or posttherapeutic response $e^{25}$. Those new concepts might not be much clearer or well defined than the placebo effect, but I think it is a sign that the placebo effect like the concept of imagination in 19th-century medicine has become too undefined and also loaded with negative connotations. Concepts sometimes become too weak or lose precision and create confusion.

This tendency to a dissolution of the concept of the placebo effect could, however, be counteracted by attempts through brain scans to localise the placebo effect in specific networks in the brain or by attempts to find a precise explanation like saying that the placebo effect is based on suppression of the acute-phase response, the so-called innate immune response ${ }^{26}$. Through scans the placebo effect can be seen in a way it has not been seen or made visible inside the body before. Some of this research is, however, not based on patients but on subjects, which is an important factor in the debate on the placebo effect. It is difficult to foresee to which extent experiments can be extrapolated to clinical situations.

The historical perspective on the placebo effect in the books from the last 20 years sometimes consists of a chapter with a short overview of between 10 and 25 pages, or it is not mentioned at all. As an extension of Shapiro and Shapiro's contribution, there is much room for improvement through detailed analysis of debates, controversies and theory-building. Books like Stanley Jackson's Care of the Psyche. A history of psychological healing cover many of the debates on imagination, suggestion, placebo effect, psychological theories, etc. in the history of medicine. This book, however, treats over 2,000 years in 500 pages, which indeed is impressive but not very thorough

22 White/Tursky/Schwartz 1985; Harrington 1997; Andersen/Claësson/Hróbjartsson/Sørensen 1997; Boström/Dahlgren 2000; Peters 2001; Guess/Kleinmann/Kusek/Engel 2002.

23 Spiro 1998; Brody 2000; Frederiksen/Lykke Christensen 2003.

24 Moerman 2002; Evans 2003; Sachs 2004. On confidence see also Harley 1999, 427ff.

25 Hart/Dieppe 1996; Hollnagel/Malterud 1995; Feinstein 2002.

26 Petrovic/Kalso/Petersson/Ingvar 2002; Evans 2003 and 2005. 
and very often based on secondary sources. There is, however, ongoing detailed work on the manipulation of influence and on psychotherapy from 1880 and onwards ${ }^{27}$.

\section{Hidden agendas?}

It cannot of course be excluded that there are different hidden agendas involved in the placebo-effect debate. Probably there are. Kaptchuk has pointed out that the writings in the 1950s about the big and powerful placebo effect could be based on an interest in promoting the use of randomised controlled trials ${ }^{28}$. The promotion of the importance of the placebo effect could also be based on an individualism that stresses the great power of the individual and supports a New Age belief in the self-organising and selfhealing abilities of the sick person. On the other hand a critical debunking claiming that this subject is a lot of fuss about nothing could also be based on an interest in promoting pharmacological, physiological and genetical views in medicine and trying to exclude more psychological and social views on the healing process. Such interests or perspectives are seldom directly stated as they might seem unscientific. A deep concern for the loss of the art of medicine is often prominent in many of the articles or books on the placebo effect:

The elements of good therapeutic style are still regularly and effectively used by many excellent practitioners, who have become an endangered species in today's "evidence-based" clinically reductionist medical world. Before members of that species become extinct, their knowledge and judgement might be discerned by clinical investigators who want to preserve the value of "therapeutic style" in the humane care of patients. ${ }^{29}$

The change from imagination via suggestion to placebo effect historically implied a shift from the concern for the abilities and faculties of the patient (imagination was seen as a faculty of the patient's mind) to a concern for what medicine or the health-care provider did to the patient. In the 1950s the placebo effect was often understood as something the placebo created. Some of the interest in the placebo effect the last 20 years can be interpreted as a renewed interest in the patient as an individual and in the patient's resources. The placebo effect has been conceptualised as something that somehow could be created or seen in the patient. This actually to a certain degree fits well with modern medicine's interest in the patient's specific genes and metabolism and an urge to create an individualised medicine, a farmaco-

27 Shamdasani 2005.

28 Kaptchuk 1998a.

29 Feinstein 2002, 429. 
genomics with an individual massgeschneiderte medicine. Perhaps a medicine that activates the centre for placebo effects, belief effects, confidence effects or caring effects could be a possibility and an unexpected mix in the future. It would probably scare some and amuse others.

\section{Bibliography}

Andersen, Lars Ole, Før Placeboeffekten: Indbildningskraftens Virkning i 1800-tallets Medicin, Thesis (København 2004)

- /M. Claësson/A. Hróbjartsson/A. N. Sørensen, Placebo. Historie, Biologi og Effekt (København 1997)

Beaumont, Jeanne Marie, Placebo Effects (New York 1997)

Beecher, Henry K., “The Powerful Placebo”, JAMA Dec. 24 (1955) 1602-1606

Boström, H./H. Dahlgren (eds), Placebo (Stockholm 2000)

Brody, Howard, Placebos and the Philosophy of Medicine (Chicago/London 1980)

- The Placebo Response (New York 2000)

Cullen, William, Clinical Lectures, Edinburgh, February-April (1772) $218 \mathrm{f}$.

Evans, Dylan, Placebo. The Belief Effect (London 2003)

- "Suppression of the acute-phase response as a biological mechanism for the placebo effect", Medical Hypotheses 64 (2005) 1-7

Faber, D. P., "Suggestion: metaphor and meaning”, Journal of the History of Behavioral Sciences 32 (1996) 16-29

Feinstein, Alvan R., "Post-therapeutic response and therapeutic 'style'. Re-formulating the 'placebo effect'”, Journal of Clinical Epidemiology 55 (2002) 427-429

Frederiksen, L./K. Lykke Christensen, Placebo. En Vej til Selvhelbredelse (København 2003)

Guess, H. A./A. Kleinmann/J. W. Kusek/L. W. Engel (eds), The Science of the Placebo. Toward an Interdisciplinary Research Agenda (London 2002)

Harley, David, "Rhetoric and the social construction of sickness and healing", Social History of Medicine 12 (1999) 407-435

Harrington, Anne (ed.), The Placebo Effect. An Interdisciplinary Exploration (Cambridge/London 1997)

Hart, J. T./P. Dippe, “Caring effects”, Lancet 347 (1996) 1606-1608

Haygarth, John, Of the Imagination, as a Cause and as a Cure of Disorders of the Body; Exemplified by Fictitious Tractors and Epidemical Convulsions (Bath/London 1801)

Hollnagel, H./K. Malterud, "Sundhedsbrøken der blev væk”, Månedsskrift for Praktisk Lagegerning 73 (1995) 693-701

Houston, W. R., "The doctor himself as a therapeutic agent", Annals of Internal Medicine 11 (1938) 1416-1425

Hróbjartsson, Asbjørn, "What are the main methodological problems in the estimation of placebo effects?", Journal of Clinical Epidemiology 55 (2002) 430-435

- /P. Gøtzsche, "Is the placebo powerless?", The New England Journal of Medicine 21 (2001) 1594-1602

Kaptchuk, Ted, "Powerful placebo: the dark side of the randomised controlled trial", Lancet 351 (1998a) 1722-1722

- "Intentional Ignorance: a history of blind assessment and placebo controls in medicine", Bulletin of the History of Medicine 72 (1998b) 389-433

Kiene, Helmuth, Kritik der klinischen Doppelblindstudie (München 1993)

Kienle, Gunver Sophia, Der sogenannte Placeboeffekt (Stuttgart 1995)

- /Helmuth Kiene, "The powerful placebo effect: fact or fiction?", Journal of Clinical Epidemiology 12 (1997) 1311-1318

Kjær-Larsen, J., "Placebo og Vurdering af Medikamenter”, Ugeskrift for Lager 48 (1956) 14281430 
Kuklich, H., "Assessing research in the history of sociology and anthropology", Journal of the History of the Behavioral Sciences 35 (1999) 227-237

Moerman, Daniel, Meaning, Medicine and the Placebo Effect (Cambridge 2002)

Pepper, O. H. Perry, “A note on the placebo", American Journal of Pharmacy 11 (1945) 409-412

Peters, David, Understanding the Placebo Effect in Complementary Medicine (London 2001)

Petrovic, P./E. Kalso/K. M. Petersson/M. Ingvar, "Placebo and the opioid analgesia - imaging a shared neuronal network", Science 295 (2002) 1737-1740

Resch, K./E. Ernst, "Research methodologies in complementary medicine: making sure it works", in: Ernst, E. (ed.), Complementary medicine. An objective appraisal (Oxford 1996) $18-30$

Risse, Günther, Hospital Life in Enlightenment Scotland (Cambridge 1986)

Sachs, Lisbeth, Tillit som bot (Lund 2004)

Shamdasani, Sonu, "Psychotherapy': the invention of a word", History of the Human Sciences 18 (2005) $1-22$

Shapiro, Arthur K., "A contribution to a history of the placebo effect", Behavioral Science 5 (1960) 109-135

- /Elaine Shapiro, The Powerful Placebo (Baltimore/London 1997)

Spiro, Howard, The Power of Hope (New Haven/London 1998)

Stocking, G. W., 'On the limits of 'presentism' and 'historicism' in the historiography of the behavioral sciences", Journal of the History of the Behavioral Sciences 1 (1965) 211-218

Stolberg, Martin, "Die Homöopathie auf dem Prüfstein", Münchner Medizinische Wochenschrift 138 (1996) 364-366

Tuke, Daniel Hack, Illustrations of the Influence of the Mind Upon the Body in Health and Disease Designed to Elucidate the Action of the Imagination (London 1872 and 1884)

White, L./B. Tursky/G. E. Schwartz (eds), Placebo. Theory, Research and Mechanisms (New York/London 1985) 